\title{
"Disabled people aren't interested in sex..."
}

That's what you'd think if you listen to some people. Since an accident whilst playing American football nearly 14 years ago, which resulted in a severe spinal cord injury, I have been involved in work to improve information for disabled people, carers and their families. But the comments I have heard from some professionals in relation to disabled people and sexuality has left me flabbergasted.

"I have worked with thousands of disabled people who had varying degrees of impairments and not one of them ever asked me any questions about sex."

This was the objection raised by one social care professional, who believed that my colleagues and I were wasting our time when we suggested setting up a project to improve information resources on sexuality and disability at our local Independent Living Centre.

\section{The European approach}

This attitude was the exact opposite to that I had witnessed when I visited a similar centre in Aarhus, Denmark only a few months before. Whilst the rest of the multinational European team were busy looking at the latest wheelchairs, beds, hoists, and so on, I was mesmerised by the display of sex aids and information positioned, quite suitably, in the bedroom display area. I was there as the co-ordinator of the Warrington Disability Information Services. On my return to the UK I suggested setting up a similar resource locally.

\section{Our project}

That was 8 years ago, and I'm glad to say that we did establish a very successful project, that included developing a resource pack, with leaflets from support organisations, such as the Spinal Injuries Association, Arthritis Care, SPOD (Sexual and Personal Relations of People with a Disability) and the Stroke Association.

Copies of the pack have been distributed to key locations across Warrington, including the local genitourinary medicine clinic, health promotions unit, health and social services centres and special schools.

\section{Awareness training \\ Alongside the information resource packs we developed a training session that highlights myths, misconceptions and general awareness surrounding sexuality and disability. The sessions are presented by disabled people in partnership with colleagues from health promotion. To date we have delivered over 40 sessions that have been attended by health and social care staff including district nurses, continence advisors, general practitioners (GPs), social workers, home care assistants and occupational therapists.}

\section{The display cupboard}

Against the advice and wishes of many people we have emulated the display of sex aids and information in the bedroom display area within our local Centre for Independent Living. Our display cupboard has become as infamous as the project itself.

\section{It's good to talk}

Through our project we have produced a leaflet, Relationships, Sexuality and Disability, which includes examples of the types of questions people ask the project team. The leaflet is given out with other disability-related information leaflets such as blue badges, transport, benefits, concessions, equipment, employment, and so on.
One real value of voluntary organisations can be underestimated, namely that of peer support. Our project highlighted the fact that talking to other people in a similar position can be of immeasurable help in putting things into perspective.

\section{Service user and service provider}

Today I work as a senior manager in the National Health Service (NHS) advising on services for disabled people and carers. Information and challenging attitudes are two of the main issues on my agenda, but our greatest successes to date have been around improving access and facilities.

\section{Barriers to services}

Many people think that it is simply a matter of providing a ramp at the entrance and an accessible toilet. But during an open forum with members at the local day centre (that I had attended for 4 years after my accident) other issues began to surface. Mrs R, who has multiple sclerosis, said that she found the embarrassment of having to have a smear test taken in the bath situated within the day centre was too much and that she "wouldn't bother in the future". The reason why she couldn't be seen at her health centre was because she couldn't get onto the examination couch; it was of the standard design and non-adjustable. The group's first recommendation was to purchase at least one fully adjustable examination couch for every health centre and GP surgery in Warrington.

Another member, $\mathrm{Mr} \mathrm{C}$, told us about a very embarrassing situation when he was told that he had contracted a sexually transmitted disease. Mr C explained that due to his hearing impairment the doctor had raised his voice to such a high level that everybody sitting in the adjoining waiting room also heard the diagnosis. It was pointed out that a hand-held induction loop system costing less than $£ 60$ could have avoided this situation. The group suggested that every health centre and GP surgery should have a hand-held portable device and a fixed system at every reception counter.

Mrs W, who is totally blind, asked if we could do anything about the situation whereby she had to rely on her 12-year-old daughter to read information leaflets to her because they weren't available in Braille. She explained that one leaflet contained very intimate details about cervical cancer. During the discussion we established that a local voluntary organisation could transcribe the information leaflet into Braille. This led to a partnership whereby we assisted the organisation to attract extra funding to purchase up-to-date technology.

\section{Disability Discrimination Act 1995}

Since October 1999 all public service providers should be providing information in accessible formats, and facilities such as induction loop systems and access to British Sign Language interpreters. Later areas of Part III Section 21 of the Disability Discrimination Act 1995 are due to be introduced in October 2004. This will place the responsibility of every NHS Trust to provide access and facilities suitable to the needs of all disabled people. Individual Trusts should have already undertaken access audits on their premises, and have prepared an action plan, setting out how they will tackle barriers encountered by disabled people, including providing access to disability awareness training for all staff. For more details on what is involved contact the Disability Rights Commission. 
Further information

Further information is available from the organisations listed below:

Arthritis Care. Tel: +44 (0) 207380 6500. www. arthritiscare.org.uk

Disability Rights Commission. Tel: +44 (0) 8457622633. www.dwp.gov.uk

Spinal Injuries Association. Tel: +44 (0) 8009800501 . www.spinal.co.uk

Sexual and Personal Relations of People with a Disability (SPOD). Tel: +44 (0) 207607 8851. www.spod-uk.org

Stroke Association. Tel: +44 (0) 207566 0330. www. stroke.org
Warrington Disability Information Services (Relationships, Sexuality and Disability Project). Tel: +44 (0) 1925240064. www.wdis.org.uk

Statements on funding and competing interests Funding. None identified.

Competing interests. None identified.

Dave Thompson, MBE

Disability and Equality Advisor, 5 Boroughs Partnership NHS Trust, Hollins Park House, Hollins Park, Hollins Lane, Winwick, Warrington WA2 8WA, UK Tel: +44 (0) 1925 664064. E-mail: dave.thompson@, 5boroughspartnership.nhs.uk

\section{ASSOCIATE MEMBERSHIP OF THE FFPRHC FOR NURSES}

Associate membership of the Faculty of Family Planning and Reproductive Health Care is open to all nurses with a special interest in contraception and reproductive health. The annual subscription is currently $£ 40$. This subscription entitles Associate Members to copies of the Journal of Family Planning and Reproductive Health Care and access to the members' enquiry service. For further information please refer to the Faculty website at www.ffprhc.org.uk (latest updates section).

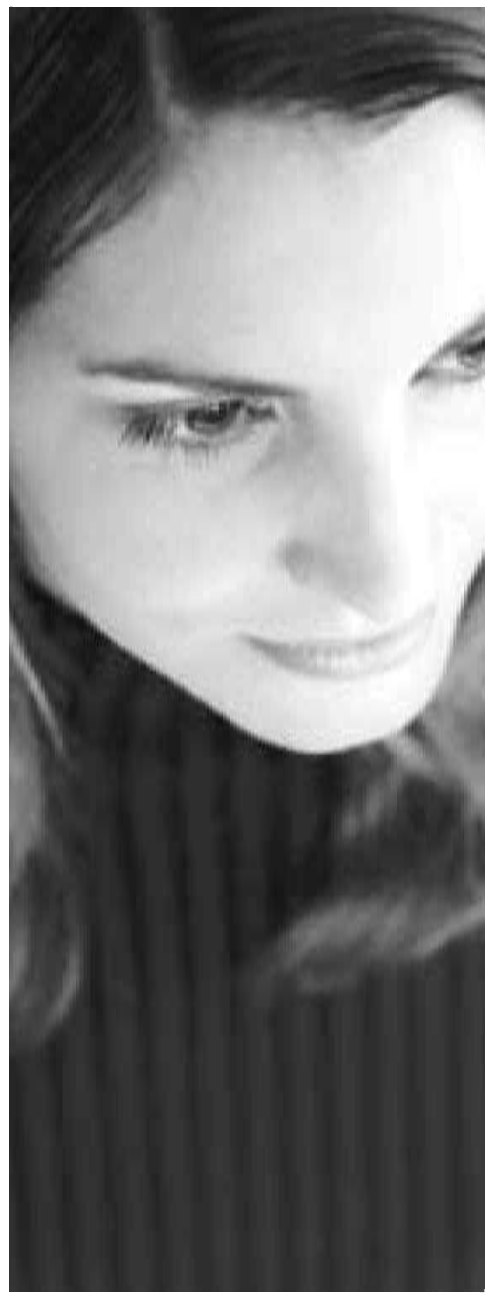

\section{Termination of Pregnancy}

\section{Fast, confidential, caring. The professional choice.}

Marie Stopes International is a leading charity in the field of family planning. We work closely with the NHS to provide termination of pregnancy services and are also happy to accept private referrals.

At centres around the UK we offer a professional and convenient service. You can trust us to take care of the patients you refer. We're discreet, confidential, sympathetic and will do everything we can to make a difficult time easier. Patients can also rely on our full aftercare service including post abortion counselling.

If your patient would like an appointment or if you would like to find out more about us, simply call the number below. We will be happy to send you an information pack containing full details of our services and some easy to use referral forms. Alternatively, you can visit our web site.

\section{Call us on 08453001212} or visit www.mariestopes.org,uk

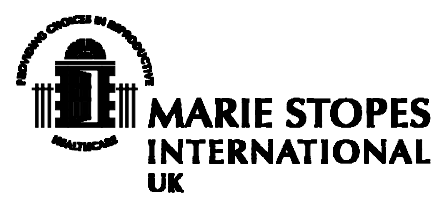

